\title{
PEMBUATAN ALAT UKUR KECEPATAN RESPON MANUSIA BERBASIS MIKROKONTROLLER AT 89S8252
}

\author{
Ika Puspita Wulandari*
}

\begin{abstract}
A human movement as a response of something is always different for each individual. However, the response is often difficult to measure because it is very flexible and sometimes are very subjective. Research was conducted with the goal to design and create tools measure the response speed of human-based mikrokontroller AT89S8252 and determine the level of accuracy tool. Measu rement tool consists of 4 switch, ie, 2, and for tester 2 for participants who tested, 2 indicator LED, buzzer, 4 buttons (menu, enter, select and cancel), speaker, and MK AT89S8252. LCD as a display. For the data on the motor response and eye response, motor ears done 9 times as much for each individual. Before the test on the motor response, eye and ear motor is done, first time on the tool dikalibrasikan using the time on the stopwatch $1 / 1000$. After that the process of testing carried out by determining the response to be conducted, the examiner pressing switch S1 or S2 switch, then LED1 or LED2 akan buzzer or light simultaneously. Participants must be tested first with a quick switch press switch S3 or S4 to stop the buzzer and the process of calculation. Step response of the data on the eyes and ears are the same. In the process of calibration equipment with time using the stopwatch $1 / 1000$ data obtained 9. The relative error deviation of $2.5 \%$ was obtained, the accuracy produced by means of measuring the speed of human response, 97.5\%. Boundary condition is the human response that is the limit of 3 is very good (one limit), normal / good (limit two), poor (limit three). In the testing of motor response in humans that use LED indicator, the data better than a motor ear response data, is due to the rapid Rambat different. LED light will reach the human eye without the lapse of time, but the sound or the sound will reach the human ear after the time interval.
\end{abstract}

Kata Kunci:Kecepatan, Gerak, Respon, Mikrokontroller

\section{PENDAHULUAN}

Dengan adanya pemanfaatan teknologi tepat guna sangat membantu dalam kelangsungan hidup manusia. Maka manusia diperintahkan oleh Allah menggunakan akal pikiran untuk berpikir agar dapat menutupi kekurangan yang terdapat pada diri manusia yang berkaitan dengan respon panca indera. Respon motorik manusia didukung oleh panca indera yang telah diberikan Allah untuk manusia. Otak manusia berisi sekitar 100 miliar sel yang tersusun secara sangat canggih. Miliaran sel itu memiliki fungsi kompleks sebagai pusat pengendali seluruh aktivitas manusia. Dalam otak inilah seluruh aktivitas manusia berpusat dan seluruh panca indera dikendalikan. Selain itu otak juga sebagai pusat pemahaman dan seluruh pengendali gerakan organ-organ tubuh manusia. Manusia yang mengalami kecelakaan dan terjadi kerusakan pada pusat kendali, maka akan mengalami masalah pada respon motorik maupun respon sensorik terhadap sesuatu. Sedangkan rangkaian kerja motorik itu berada di kulit otak bagian depan. Dalam kehidupan sekarang ini manusia telah mencapai perkembangan yang luar biasa pesatnya. Dengan perkembangan segala ilmu pengetahuan maka berkembang pula ilmu fisika di dunia pendidikan. Suatu gerak manusia sebagai suatu respon dari sesuatu merupakan hal yang selalu berbeda pada setiap individu. Suatu respon manusia

\footnotetext{
${ }^{(*)}$ Pemerhati fisika
} 
memiliki sifat cepat dan lambat. Beberapa pekerjaan membutuhkan respon yang cepat, terutama dalam menghadapi suatu permasalahan yang kritis. Seorang penjaga gawang dalam persepak-bolaan harus mempunyai gerakan yang cepat dan tepat terhadap kedatangan bola yang menuju ke gawangnya.

Namun seringkali respon tersebut sulit untuk diukur karena sangat flexible sekali dan terkadang bersifat subjektif. Untuk itu maka diperlukan suatu alat ukur untuk menentukan cepat atau lambatnya kecepatan respon pada manusia tersebut.Penelitian ini bertujuan untuk membuat Alat Pengukur Kecepatan Respon Manusia Dengan Menggunakan Mikrokontroler Jenis AT89S8252.

\section{KAJIAN TEORI}

Dalam ilmu fisika pengertian gerak adalah suatu perubahan tempat kedudukan pada suatu benda dari titik keseimbangan awal. Sebuah benda dikatakan bergerak jika benda itu berpindah kedudukan terhadap benda lainnya baik perubahan kedudukan yang menjauhi maupun yang mendekati. Beberapa macam gerak antara lain gerak semu atau relatif yang pengertiannya gerak yang sifatnya seolah-olah bergerak atau tidak sebenarnya (ilusi), gerak ganda merupakan gerak yang terjadi secara bersamaan terhadap benda-benda yang ada di sekitarnya, gerak lurus adalah gerak pada suatu benda melalui lintasan garis lurus. Gerak lurus ini ada dua macam lagi yaitu GLB dan GLBB. Gerak lurus beraturan adalah gerak suatu benda yang lurus beraturan dengan kecepatan yang tetap dan stabil. Gerak lurus berubah beraturan adalah gerak suatu benda yang tidak beraturan dengan kecepatan yang berubah-ubah dari waktu ke waktu. Dengan menerapkan hukum gerak Newton yang mengaitkan gaya-gaya yang berperan dengan keadaan geraknya.

\section{Gerak Reflek Pada Manusia}

Gerak refleks adalah gerak yang dihasilkan oleh jalur saraf yang paling sederhana. Jalur saraf ini dibentuk oleh sekuen neuron sensor, interneuron, dan neuron motor, yang mengalirkan impuls saraf untuk tipe reflek tertentu. Gerak refleks yang paling sederhana hanya memerlukan dua tipe sel saraf yaitu neuron sensor dan neuron motor. Gerak refleks disebabkan oleh rangsangan tertentu yang biasanya mengejutkan dan menyakitkan. Gerak refleks terjadi apabila rangsangan yang diterima oleh saraf sensori langsung disampaikan oleh neuron perantara (neuron penghubung). Gerak pada umumnya terjadi secara sadar, namun ada pula gerak yang terjadi tanpa disadari yaitu gerak refleks. Impuls pada gerakan sadar melalui jalan panjang, yaitu dari reseptor ke saraf sensori dibawa ke otak untuk selanjutnya diolah oleh otak kemudian hasil olahan oleh otak, berupa tanggapan yang dibawa oleh saraf motor sebagai perintah yang harus dilaksanakan oleh efektor. Sedangkan gerak refleks berjalan sangat cepat dan tanggapan terjadi secara otomatis terhadap rangsangan, tanpa memerlukan kontrol dari otak. Gerak refleks yang paling sederhana memerlukan dua tipe sel saraf, yaitu neuron sensorik dan neuron motorik. Gerak refleks bekerja bukanlah dibawah kesadaran dan kemauan seseorang. Pada gerak refleks, impuls melalui jalan pendek atau jalan pintas yaitu dimulai dari reseptor penerima rangsang, kemudian diteruskan oleh saraf sensori ke pusat saraf, diterima oleh sel saraf 
penghubung (asosiasi) tanpa diolah didalam otak langsung dikirim tanggapan ke saraf motor untuk disampaikan ke efektor, yaitu otot atau kelenjar, jalan pintas ini disebut lengkung refleks. (Wilarso, joko: 2001)

\section{Mekanisme Gerak Reflek Pada Manusia}

Gerak terjadi melalui mekanisme rumit dan melibatkan banyak bagian tubuh. Terdapat banyak komponen - komponen tubuh yang terlibat dalam gerak, baik disadari maupun tidak disadari. Seluruh mekanisme gerak yang terjadi ditubuh manusia tak lepas dari peranan sistem saraf. Sistem saraf ini tersusun atas jaringan saraf yang di dalamnya terdapat sel-sel saraf atau neuron. Meskipun sistem saraf tersusun dengan sangat kompleks, tetapi sebenarnya hanya tersusun atas dua jenis sel, yaitu sel saraf dan sel neuroglia. Adapun berdasarkan fungsinya sistem saraf itu sendiri dapat dibedakan atas tiga jenis. Sel saraf sensorik adalah sel yang membawa impuls berupa rangsangan dari reseptor (penerima rangsangan), ke sistem saraf pusat (otak dan sumsum tulang belakang). Sel saraf sensorik disebut juga dengan sel saraf indera, karena berhubungan dengan alat indra. Sel saraf motorik berfungsi membawa impuls berupa tanggapan dari susunan saraf pusat (otak atau sumsum tulang belakang) menuju kelenjar tubuh. Sel saraf motorik disebut juga dengan sel saraf penggerak, karena berhubungan erat dengan otot sebagai alat gerak. Sel saraf penguhubung disebut juga dengan sel saraf konektor, hal ini disebabkan karena fungsinya meneruskan rangsangan dari sel saraf sensorik ke sel saraf motorik. Hal ini berbeda sekali dengan mekanisme gerak biasa. Gerak biasa rangsangan akan diterima oleh saraf sensorik dan kemudian disampaikan langsung ke otak. Dari otak kemudian dikeluarkan perintah ke saraf motori sehingga terjadilah gerakan. Pada gerak biasa gerakan itu diketahui atau dikontrol oleh otak. Sehingga gerak biasa adalah gerak yang disadari.(Wilarso, joko: 2001)

\section{Otak}

Otak terdiri dari sekitar (10.000.000.000) sel syaraf yang saling berhubungan. Sel syaraf mempunyai cabang struktur input (dendrites), sebuah inti sel dan percabangan struktur output (axon). Otak merupakan suatu alat yang kompleks, taklinear dan prosesnya paralel yang mengolah isyarat masukan menjadi suatu keluaran yang dapat dikenali untuk proses selanjutnya. Maka, jaringan syaraf secara umum adalah mesin yang dirancang sebagai model sebagaimana otak melakukan tugasnya yang dapat berupa perangkat-keras maupun perangkat-lunak. Dibawah ini adalah gambar jaringan system saraf pada manusia.

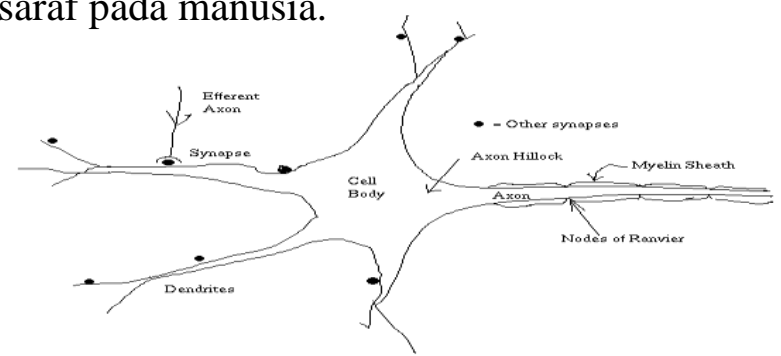

Gambar 1. Susunan Saraf Manusia 
Visual cortex tersusun dari beberapa lapisan. Lapisan pertama disebut dengan Visual area 1 (V1). V1 akan mengirimkan informasi melalui dua jalur yang disebut dengan Dorsal Stream dan Ventral Stream. Ventral stream berperan untuk identifikasi persepsi objek (perceptual identification of objects), yang berupa bentuk, ukuran, warna dan tekstur (object vision). Sedangkan Dorsal stream berperan untuk mengolah informasi spasial objek (spatial vision). Bagian Dorsal inilah yang menyebabkan kita dapat melihat objek bergerak. Melalui jalur Ventral, informasi akan dilanjutkan masuk kedalam visual area 2 (V2), dan selanjutnya masuk kedalam visual area 4 (V4) dan berakhir pada bagian Inferior-Temporal lobe (IT). Sedangkan melalui jalur Dorsal, informasi akan dilanjutkan masuk ke dalam V2 dan masuk kedalam dorsomedial area dan Middle Temporal (MT) area (V5). Dengan demikian informasi visual diproses oleh otak manusia melalui beberapa tahap yang dilakukan secara hirarki. Mulai dari bagian V1 dimana objek terkecil yang sudah tidak bisa dibagi lagi (atomik) disimpan berupa edge/corner, selanjutnya akan masuk ke dalam V2 dalam bentuk grup-grup feature yang sudah memiliki bentuk objek (intermediate visual forms) dan terakhir akan masuk ke dalam Inferior Temporal (IT). Pada bagian IT ini objek sudah dapat diidentifikasi bentuknya (high level object).

\section{Kecepatan Respon Manusia}

Kecepatan respon manusia ditentukan oleh kualitas sistem sarafnya, yang menghubungkan antara otak sebagai pusat kendali dengan organ-organ di seluruh tubuh. Jika susunan sarafnya tidak stabil, maka kecepatan perintah itu akan terganggu bahkan mengalami kelambatan. Demikian pula jika kualitas sarafnya buruk, kecepatan respon juga akan menurun. Salah satu keanehan pada sistem saraf berdampak pada kualitas sarafnya. Secara umum dapat dikatakan bahwa perilaku ialah suatu respons dinamika suatu sistem suatu suatu rangsangan melalui mekanisme tertentu. Pada dasarnya kecepatan respon manusia didukung dengan saraf sensorik dan saraf motorik. Adapun batas nilai kecepatan respon manusia terdiri dari 3 batas dan 3 kondisi. Tiga kondisi batas reaksi tersebut meliputi sangat baik, baik atau normal,dan buruk

Tabel 1. Tabel nilai batas kecepatan respon manusia

\begin{tabular}{|c|c|c|}
\hline No. & Batas & Reaksi/kondisi \\
\hline 1 & $0-300$ mdetik & Sangat baik \\
\hline 2 & $400-650$ mdetik & Baik/normal \\
\hline 3 & $651-999$ mdetik & Buruk \\
\hline
\end{tabular}

Sumber: Teknik Elektro Universitas Gunadarma

Sistem saraf merupakan satu sistem dalam tubuh sebagai media komunikasi antar sel maupun organ. Sistem saraf juga sangat mempengaruhi kecepatan respon manusia terhadap rangsangan apapun. 


\section{Definisi Transistor}

Transistor adalah komponen elektronik yang memiliki tiga sambungan. Ketiga sambungan tersebut memiliki nama kolektor, basis dan emitor. Untuk transistor pnp semua harus harus dihitung terbalik dan voltase-voltase harus menjadi terbalik. Berarti $V_{B E}$ dan $V_{C E}$ menjadi negatif atau menjadi $V_{B E}$ (voltase emitor-basis) dan $V_{C E}$ (voltase emitor-kolektor) (Malvino:2003).

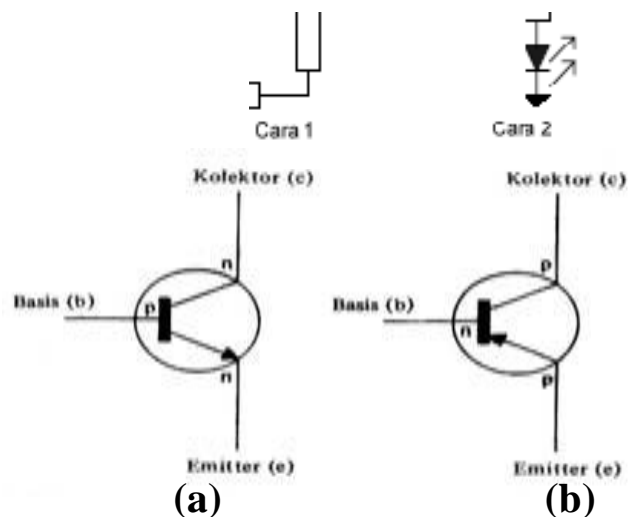

Gambar 2. (a) n p n, (b) p n p

Pada gambar 2.1(a) simbol sirkit untuk n p n. Sedangkan gambar yang b simbol untuk $\mathrm{p} \mathrm{n}$ p. Perbedaan gambar diatas terletak pada arah panah di ujung emitter. Kolektor dan emitter merupakan bahan $\mathrm{n}$ dan lapisan di antara mereka merupakan jenis p. Transistor bekerja dalam satu arah, saling menghubungkan ujung-ujung kolektor dan emitter karena terbuat dari jenis bahan yang sama. Kolektor berukuran lebih besar untuk penyerapan panas. Ketika transistor digunakan hampir semua panas yang terbentuk berada pada sambungan basis kolektor yang harus mampu menghilangkan panas. ( Roger : 1995)

\section{LED (Light Emitting Diode)}

LED merupakan singkatan dari Light Emitting Diode. Led merupakan piranti yang vital dalam teknologi electroluminescent seperti untuk aplikasi teknologi. Dari sisi penggolongan, LED merupakan komponen aktif bipolar semikonduktor, karena itu hanya mampu mengalirkan arus dalam satu arah saja. LED banyak digunakan untuk indikator dan transmisi sinyal atau bahkan untuk penerangan. LED dapat menyala pada arus searah (DC) maupun arus bolakbalik (AC), yang membedakan adalah kontinyuitas. Pada arus DC led menyala secara kontinyu, sedangkan pada arus AC led akan menyala secara tidak kontinyu (nyala-padam secara periodik). Pada aplikasinya, led dapat dikendalikan dengan 2 cara yaitu dengan menyambungkan anoda ke catu positif dan katoda ke keluaran rangkaian. Pada cara pertama, led akan menyala jika keluaran rangkaian berlogika 0 (terhubung ke ground). Sedangkan pada cara kedua led akan menyala jika keluaran berlogika 1 (terhubung dengan catu positif). Led biasa berfungsi sebagai lampu indikator pada saat sensor bekerja, dan bekerja pada bias forward.(Woolard: 2006) 


\section{Mikrokontroller AT89S8252}

Mikrokontroler adalah mikrokomputer chip tunggal yang dirancang secara spesifik untuk aplikasi-aplikasi control dan bukan untuk aplikasi-aplikasi serbaguna. Perangkat ini seringkali digunakan untuk memenuhi kebutuhan control tertentu, seperti mengendalikan sebuah penggerak motor. Mikrokomputer chip tunggal, di lain pihak, biasanya melaksanakan beragam fungsi yang berbeda dan dapat mengendalikan beberapa proses dalam waktu yang bersamaan. Aplikasi-Aplikasi yang tipikal meliputi control perangkat-perangkat peripheral meliputi control perangkatperangkat peripheral seperti motor, penggerak, printer, dan komponen-komponen subsistem minor. Mikrokontroller berfungsi untuk mengontrol kerja suatu sistem. Di dalam mikroprosesor, tetapi dengan penambahan perangkat-perangkat lain seperti ROM, RAM, PIO, SIO, Counter dan rangkaian Clock. Mikrokontroller didesain dengan instruksi-instruksi yang lebih luas dan 8 bit instruksi digunakan untuk membaca data instruksi dari internal memory ke ALU. Banyak instruksi yang digabung dengan pin-pin pada chip-nya.

Berikut ini kemampuan dari mikrokontroler AT89S8252 sebagai berikut:

- 8-Bit mikrokontroler

- 8 kbytes Programmable Flash Memory dengan kemampuan 1000 kali pemrograman atau penghapusan

- 3 buah 16 bit Timer / Counter

- 9 sumber interupt

- Jangkauan operasi 0-24 MHz

- 256x8-bit Internal Random Access Memory (RAM)

- 32 jalur input / output

- On-Chip Oscillator dan Clock circuitry

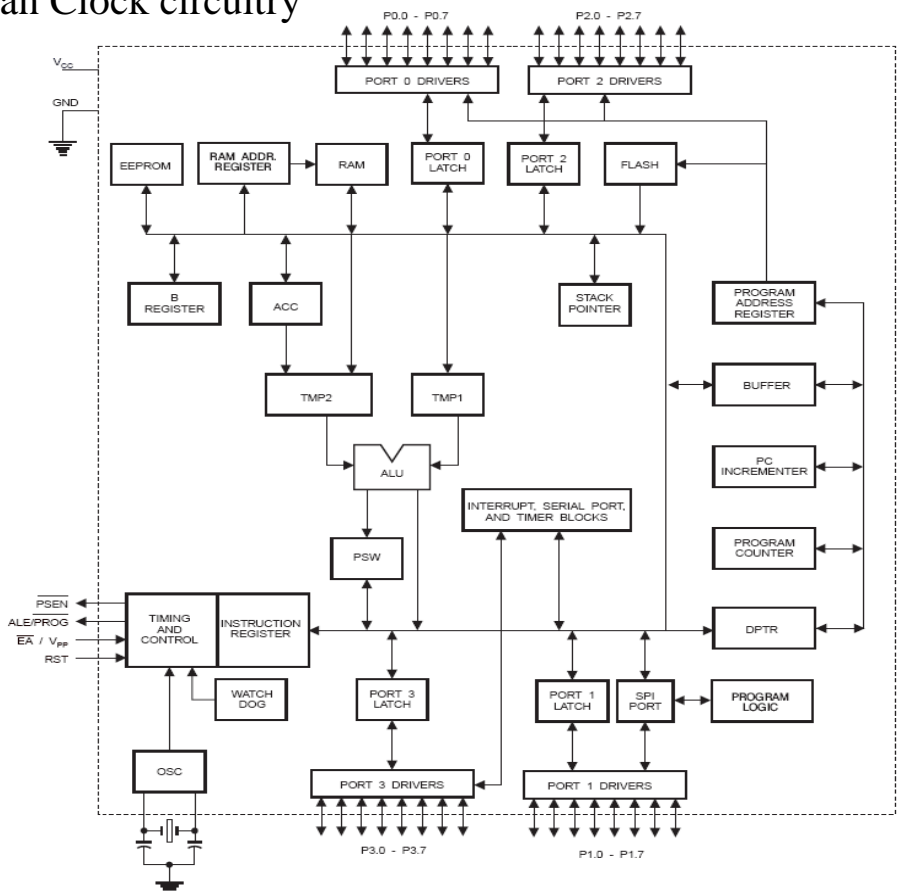

Gambar 3.Arsitektur AT89S8252

(Sumber: www.atmel.com) 


\section{LCD (Liquid Crystal Dispaly) M1632}

LCD (Liquid Crystal Display) merupakan salah satu jenis tampilan yang dapat digunakan untuk menampilkan angka (numerik) atau karakter. LCD terdiri atas tumpukan tipis dari dua lembar kaca dengan pinggiran yang tertutup rapat. Antara dua lembar kaca tersebut diberi bahan kristal cair (Liquid Crystal) yang tembus cahaya. Permukaan luar dari masing-masing keping kaca mempunyai lapisan penghantar tembus cahaya seperti oksida timah atau oksida indium. (Woollard, 2006) Disini penulis menggunakan LCD M1632 keluaran Seiko Instrument. LCD Display Module M1632 buatan Seiko Instrument Inc terdiri atas dua bagian, yang pertama merupakan panel LCD sebagai media penampil informasi dalam bentuk huruf/angka dua baris, masingmasing baris bisa menampung 16 huruf/angka. Bagian kedua merupakan sebuah sistem yang dibentuk dengan mikrokontroler yang ditempelkan dibalik panel LCD, berfungsi mengatur tampilan informasi serta berfungsi mengatur komunikasi M1632 dengan mikrokontroler.

LCD tipe M1632 mempunyai spesifikasi perangkat keras, sebagai berikut :

-16 karakter dan 2 baris tampilan yang terdiri dari $5 \times 7$ dot matriks ditambah dengan kursor

-Pembnagkit karakter ROM untuk 192 jenis karakter

-Pembangkit karakter RAM untuk 8 jenis karakter

-80 x 8 display data RAM (maksimum 80 karakter)

-Oscillator dalam modul

-Catu daya 5 volt

-Otomatis reset saat catu daya dinyalakan

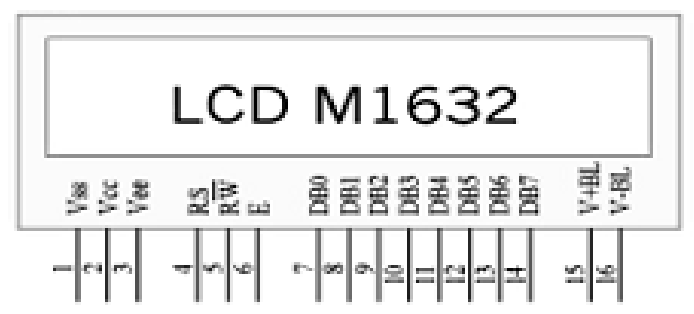

Gambar 4. LCD M1632

(Sumber : www.robotindonesia.com)

\section{Transformator}

Transformator adalah sebuah alat yang terdiri dari lilitan primer, lilitan sekunder dan inti yang berfungsi untuk mengubah tegangan listrik. Transformator dirancang sedemikian rupa sehingga seluruh fluks magnet yang dihasilkan arus pada kumparan primer dapat masuk ke kumparan sekunder. Transformator memegang peranan penting dalam transmisi listrik.

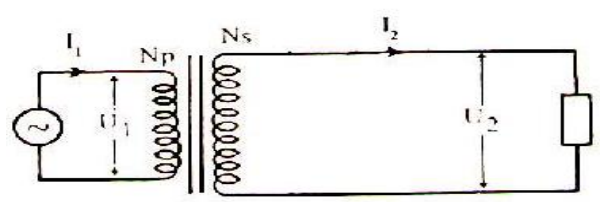

Gambar 5. Transformator 


\section{Kapasitor}

Kapasitor adalah komponen elektronika yang dapat menyimpan muatan listrik. Struktur sebuah kapasitor terbuat dari 2 buah plat metal yang dipisahkan oleh suatu bahan dielektrik. Bahan-bahan dielektrik yang umum dikenal misalnya udara vakum, keramik, gelas dan lain-lain. Jika kedua ujung plat metal diberi tegangan listrik, maka muatan-muatan positif akan mengumpul pada salah satu kaki (elektroda) metalnya dan pada saat yang sama muatan-muatan negatif terkumpul pada ujung metal yang satu lagi. Muatan positif tidak dapat mengalir menuju ujung kutup negatif dan sebaliknya muatan negatif tidak bisa menuju ke ujung kutup positif, karena terpisah oleh bahan dielektrik yang non-konduktif. Muatan elektrik ini tersimpan selama tidak ada konduksi pada ujung-ujung kakinya. Gambar dibawah ini adalah gambar prinsip kerja kapasitor.

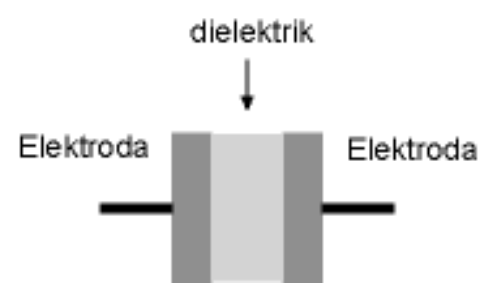

Gambar 6. Prinsip dasar kapasitor

\section{METODE PENELITIAN}

\section{Alat dan Bahan}

1. LED (Light Emiting Diode)

2. LCD M1632 (Liquid Crystal Display)

3. Saklar

4. PCB

5. Mikrokontroler AT89S8252

6. Kabel

7. Kotak

8. Tombol

9. Speaker

10. Trafo

11. Kapasitor

12. Transistor

\section{Diagram Blok Alat}

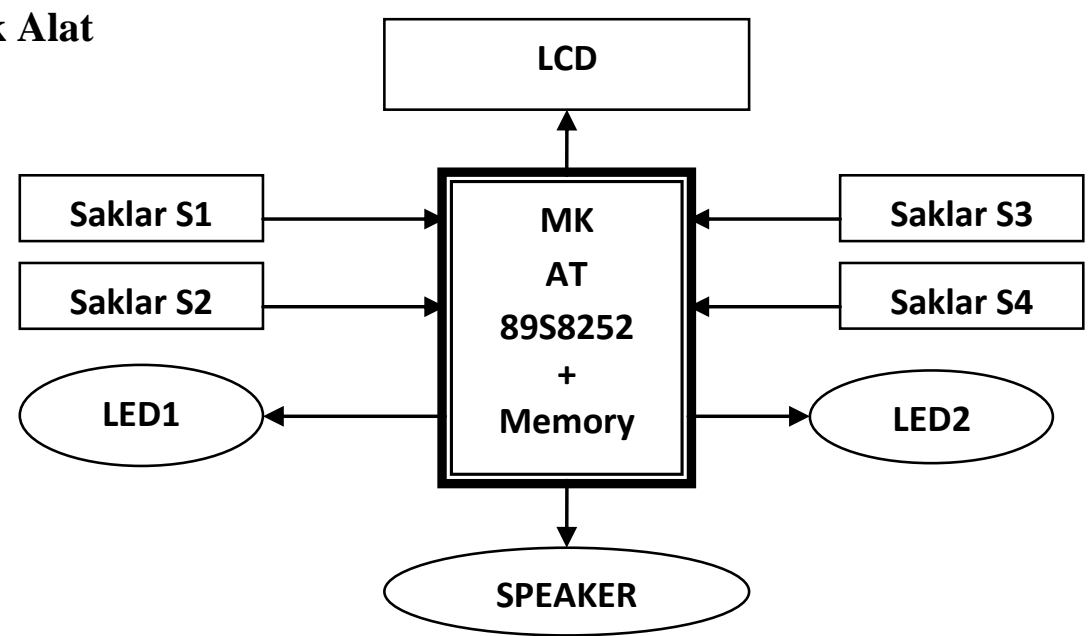

Gambar 7. Diagram Blok Sistem Keseluruhan 
Prinsip kerja dari diagram blok alat diatas antara lain:

1. Alat dihidupkan maka rangkaian mikrokontroler dalam keadaan stanby.

2. LCD menampilkan angka 000 dan akan melakukan penyimpanan data dalam memori.

3. Penekanan saklar S1 atau S2 yang dilakukan oleh penguji akan mengaktifkan indikator LED1 atau LED2 dan bel.

4. Jika saklar S1 ditekan maka indikator LED1 yang menyala dan jika saklar S2 yang ditekan maka LED2 yang menyala.

5. Pada saat LED1 atau LED2 dan bel menyala maka mikrokontroler akan melakukan hitungan dari 000-001-002 dengan kecepatan 1 milidetik.

6. Peserta yang diuji harus menekan saklar S3 atau saklar S4 untuk menghentikan perhitungan yang ditampilkan dalam tampilan LCD.

7. Jika saklar S1 yang ditekan maka peserta yang diuji harus menekan saklar S3 begitu juga dengan saklar S2 ditekan maka S4 yang ditekan

\section{Pembuatan Perangkat Lunak}

Pengendalian sistem yang berpusat pada mikrokontroller sepenuhnya diatur oleh program utama mikrokontroller. Dalam program utama ini terdapat sub rutin-sub rutin yang mengendalikan beberapa sistem yang mendukung kinerja mikrokontroller. Algoritma menu program secara garis besar dapat dilihat pada gambar 3.3. Sedangkan algoritma secara keseluruhan berada di lampiran. Pertama kali program dijalankan, ditekan start terus memilih respon yang akan dilakukan pengujian, memilih saklar 1 atau 2, setelah itu LED atau tone menyala, start counter, memilih saklar stop, stop counter, simpan, tampilkan. Dalam program utama ini terdapat sub rutin-sub rutin yang mengendalikan beberapa sistem yang mendukung kinerja mikrokontroller. Selanjutnya program akan memanggil sub rutin-sub rutin inisialisasi diantaranya:

a) Inisialisasi port untuk menginisialisasi port-port yang digunakan sebagai jalur pemilihan respon.

b) Inisialisasi saklar dan LED untuk menginisialisasa jalur/port yang digunakan sebagai output.

c) Inisialisasa LCD (tampilan awal LCD). Inisialisasi pada LCD berfungsi agar LCD dapat berjalan dengan baik

\section{Teknik Pengambilan Data}

\section{Validitas Waktu}

Sebelum proses pengujian pada respon motorik mata dan respon motorik telinga dilakukan, terlebih dahulu waktu pada alat dikalibrasikan dengan menggunakan waktu pada stopwatch 1/1000. Langkah yang dilakukan dalam proses pengkalibrasian ini adalah ketika alat dihidupkan dan dilakukan proses perhitungan waktu, maka stopwatch 1/1000 dinyalakan secara bersamaan dengan proses perhitungan waktu pada alat. Langkah itu dilakukan sebanyak 9 kali dalam proses pengkalibrasian.

\section{Proses Pengambilan Data}

Pengambilan data pada penelitian ini menggunakan beberapa variabel dengan individu yang berbeda. Dengan langkah - langkah sebagai berikut : 
1. Penguji memilih respon yang akan dilakukan untuk pengujian. Kemudian penguji menyalakan saklar S1 atau saklar S2, maka LED1 atau LED2 atau bel akan menyala. Bersamaan dengan penekanan saklar maka mikrokontroler melakukan perhitungan dan ditampilan dalam LCD.

2. Peserta yang diuji pertama harus dengan cepat menekan saklar S3 atau saklar S4 untuk menghentikan proses perhitungan

3. Setelah itu hasilnya dapat dilihat pada tampilan LCD.

4. Maka diperoleh data kecepatan respon peserta yang diuji.

5. Dari serangkaian langkah diatas didapatkan nilai rata-rata dan kondisi batas atas kecepatan respon manusia yang diuji

6. Pengujian ini dilakukan sebanyak 9 kali untuk setiap individu.

\section{Teknik Analisa Data}

Untuk analisa data dengan dicari rata - rata dari data peserta yang diuji. Dengan cara sebagai berikut:

$$
\begin{aligned}
\text { Rata-rata }= & \frac{\sum \text { DataTimer }}{9} \\
& \frac{\sum_{1}^{9}=1 \text { datatimer }}{9}
\end{aligned}
$$

Dari data perhitungan, didapatkan nilai rata-rata kecepatan respon pada manusia. Nilai rata-rata akan dijadikan sebagaiindikasi batas. Dalam pengukuran ini ada dua kriteria atau respon yang diberikan yaitu respon benar atau salah.

\section{ANALISIS UJI COBA}

Pengujian pada respon mata ini dilakukan dengan cara saklar penguji ditekan lalu LED menyala maka peserta uji harus menekan saklar yang berada tepat pada indikator LED yang menyala untuk menghentikan perhitungan. Hasil data dari alat kecepatan respon manusia bermacam-macam. Pada respon mata di dapatkan nilai pada kondisi batas satu yang responnya sangat baik dengan nilai rata-rata 241 milidetik, 371 milidetik. Ada 2 peserta uji yang memperoleh nilai pada batas kondisi sangat baik. Dan yang mendapatkan nilai pada batas kondisi baik/normal ada 3 peserta uji dengan nilai rata-rata dapat dilihat pada lampiran 7. Batas kondisi buruk yang diperoleh dengan nilai rata-rata yang dihasilkan adalah 793 milidetik. Hasil data pada alat tersebut dalam satuan milisecon (ms). Pada pengujian kecepatan respon khususnya respon mata semua peserta yang diuji berada pada respon yang benar.

Sedangkan nilai kecepatan respon motorik telinga pada manusia yang menggunakan suara juga bervariasi. Ada yang pada kondisi batas satu, batas dua dan kondisi batas tiga. Pengujian terhadap kecepatan respon motorik telinga pada manusia ini peserta yang diuji banyak yang nilai rata-ratanya pada kondisi batas dua atau baik/normal. Ada pula yang mendapatkan nilai yang kondisi batasnya buruk. Sebanyak 4 orang yang mendapatkan nilai pada batas kondisi normal/baik dan untuk 1 orang mendapatkan batas kondisi yang buruk. Dan 2 orang mendapatkan kondisi batas sangat baik. Sedangkan batas kondisi yang buruk dengan nilai 708 milidetik.

Untuk pengujian kecepatan respon motorik telinga dilakukan dengan penguji 
menekan saklar maka secara bersamaan tone pada alat tersebut berbunyi. Maka peserta yang diuji harus menekan tombol yang terdapat pada alat untuk menghentikan perhitungan dan mematikan suara. Pengujian pada respon motorik telinga ini peserta uji melakukan penekan tombol untuk menghentikan perhitungan pada respon benar. Dalam pengujian respon motorik telinga dan respon motorik mata terdapat 2 respon yaitu respon benar dan respon salah. Respon salah disini adalah peserta uji menekan tombol tapi bukan pada tombol yang benar. Dalam hal ini data yang dihasilkan tetap tersimpan dan perhitungan juga berhenti tetapi nilai yang diperoleh masuk dalam penyimpanan memori pada respon salah. Respon salah terjadi karena kurang berkonsentrasi dan kepekaan terhadap suara yang ditimbulkan oleh alat tersebut kurang sempurna.

Kecepatan respon motorik mata dan motorik telinga pada manusia mendapat nilai baik atau dikatakan baik jika angka yang ditampilkan pada LCD menunjukkan angka sekecil mungkin antara 0 milidetik sampai dengan 399 milidetik. Dari data kecepatan respon manusia berupa mata dan telinga tersebut di dapatkan beberapa analisa. Nilai yang dihasilkan pada respon motorik telinga tidak sama dengan nilai pada pengujian respon mata. Apabila peserta uji mendapatkan hasil yang sangat baik pada pengujian respon motorik mata, belum tentu hasil pada pengujian respon motorik telinga mendapatkan batas kondisi yang sangat baik juga. Perbedaan hasil nilai pada pengujian respon motorik mata dan respon motorik telinga pada manusia terletak pada beda laju cahaya dan laju bunyi yang berbeda-beda.

Pada pengujian respon mata pada manusia yang menggunakan indikator LED, datanya lebih baik dari data respon telinga, itu dikarenakan adanya cepat rambat yang berbeda. Cahaya LED akan mencapai mata manusia tanpa selang waktu, tetapi bunyi atau suara akan mencapai telinga manusia setelah interval waktu. Adapun nilai laju cahaya adalah $300.000 \mathrm{~km}$ per detik. Jadi, bunyi mencapai telinga manusia lebih lambat daripada cahaya. Pada saat gelombang bunyi mencapai telinga manusia, terjadi suatu penerimaan dan dikatakan terdengar. Bagian luar dan bagian dalam telinga sebenarnya adalah penerima gelombang suara, yang sinyalnya diteruskan ke otak dan kemudian dianalisis. Kemampuan telinga menghasilkan frekuensi tinggi yang teramati berdasarkan pada pemanfaatan dari impuls saraf dalam pusat pendengaran. Kecepatan gelombang bunyi diperoleh dari hasil kali antara frekuensi dan panjang gelombang. Selain itu v dengan bantuan pengukuran selang waktu, suatu paket gelombang bunyi dapat ditentukan misalnya pada petir dan dentuman suatu ledakan. Nilai kecepatan gelombang bunyi pada udara sebesar 331,4 m/dtk.

\section{KESIMPULAN}

1. Mikrokontroller AT89S8252 dapat diaplikasikan pada alat ukur kecepatan respon manusia dengan memasang 4 saklar, serta basis frekuensi osilator $12 \mathrm{Mhz}$.

2. Alat ukur kecepatan respon manusia menggunakan mikrokontroller AT89S8252 terdiri dari saklar, 4 tombol antara lain, menu, enter, select, dan cancel, 2 buah indikator LED dan nada, MCU AT89S8252, serta LCD. Prinsip kerja alat diatas adalah penguji memilih respon yang akan ilakukan untuk pengujian. Kemudian penguji menyalakan saklar S1 atau saklar S2, maka LED1 atau LED2 atau nada berbunyi. Bersamaan dengan penekanan saklar maka mikrokontroler melakukan perhitungan dan ditampilan dalam LCD. Peserta yang diuji harus dengan cepat menekan saklar S3 atau saklar S4 untuk menghentikan 
proses perhitungan. Kemudian data diolah oleh MCU, setelah itu nilai dari pengujian awal sampai akhir dan nilai rata-rata, hasilnya ditampilkan pada tampilan LCD.

3. Hasil pengujian kecepatan respon mata pada manusia didapatkan kondisi yang sangat baik (batas satu), dengan nilai rata-rata yang dihasilkan adalah 241 milidetik, 371 milidetik. Dan juga didapatkan pada batas buruk dengan nilai 793 milidetik. Sedangkan pada pengujian respon telinga didapatkan kondisi batas sangat baik, normal dan buruk. Itu disebabkan karena kurang konsentrasi pada saat pengujian dan belum bias memahami dan membedakan suara yang keluar dari speaker. Tingkat ketajaman dan kepekaan manusia terhadap sesuatu itu berbedabeda dan itu juga dapat mempengaruhi pada waktu pengujian. Pengendalian sistem yang berpusat pada mikrokontroller sepenuhnya diatur oleh program utama mikrokontroller. Dengan program yang telah dibuat, berapa pun kecepatan respon manusia dari umur berapa pun dan panca indera yang berbeda akan dapat terukur dan hasilnya ditampilkan melalui LCD. Dan juga dapat untuk mengetahui penyebab dari hasil nilai kecepatan rata-rata pada kondisi batas yang bermacam-macam.

4. Kalibrasi yang dilakukan menghasilkan nilai simpangan terkecil, terbesar dan simpangan rata-rata, deviasi $\mathrm{X}$, dan kesalahan relatif simpangan. Simpangan terkecil sebesar 0,3, simpangan terbesar yakni 9,3, simpangan rata-rata yaitu 2,7. Adapun nilai deviasi yang dihasilkan adalah 4, sedangkan kesalahan relatif simpangan yang diperoleh sebesar $2,5 \%$.

\section{DAFTAR PUSTAKA}

Agfianto, Eko Putra. 2002. Belajar Mikrokontroler AT89S8252 (Teori dan Aplikasinya). Cetakan pertama. Gava Media.

Anonymous. 2005. Mekanisme Gerak Otot Pada Manusia. http///www. Wikimedia. com. 2008. Sistem Gerak Manusia. http///www. Crayonpedia. Org/mw/2.

2008. Kecepatan Respon Manusia dan Aksi Cepat Tanggap. $\mathrm{http} / / / \mathrm{www}$. Wikibooks.com.

Annonymous. 2003. LCD M1632. www.robotindonesia.com tanggal 2 Desember 2008 Annonymous. 2002. AT89S8252. www.atmel.com. Tanggal 11 November 2008

Blocher, Richard. 2004. Dasar Elektronika. Edisi Kedua. Yogyakarta.

Giancoli, Douglas C. 1999. Fisika Edisi Kelima. Erlangga: Jakarta.

Ilyas, Sidarta DSM. 1997. Ilmu Penyakit Mata. Jakarta: Fakultas Kedokteran Universitas Indonesia.

Malvino, Paul Albert. 2003. Prinsip-Prinsip Elektonika. Salemba: Jakarta

Paulus, Andi Nalwan. 2003. Panduan Praktis teknik Antarmuka Dan Pemograman. Elex Media Komputindo.

Roger L, Tokheim. 1995. Elektronika digital Edisi Kedua. Erlangga.

Sears, Zemansky. 1982. Fisika Untuk Universitas 1. Binacipta: Bandung.

Soedojo, Peter. 1999. Fisika Dasar Edisi Pertama Cetakan Kedua. Yogyakarta.

Roger L, Tokheim. 1995. Rangkaian Mikroelektronik. Erlangga: Jakarta.

Woolard, Barry. 2006. Elektronika Praktis Cetakan Keenam. Pradnya Paramita.

Wilarso,joko. 2001. Biologi Pendidikan Dasar. Erlangga: Jakarta. 